Canadian Journal of Family and Youth, 13(3), 2021, pp. 350-355

ISSN 1718-9748@ University of Alberta

http://ejournals,library,ualberta.ca/index/php/cjfy

\title{
Children and the Internet: Effects, Outcomes, and Solutions
}

\author{
Kendra Steventon, MacEwan University
}

\section{Introduction}

The internet was a phenomenon introduced to the public in the early 1990s that allowed people to communicate across substantial distances. Today, the internet is used daily by millions of people worldwide. The internet is an interactive platform used for social media, online gaming, shopping, and many other outlets. The implications of the internet reach far beyond other forms of passive media such as television and radio. The powerful appeal of the internet has led many to question its consequences. The internet has been found to have the potential to change the entire way that one lives. This includes how they perceive their own health, well-being, and stress levels When considering the internet's strong effect on adults, researchers are left questioning what impacts it can have on children. This area is beginning to see increased rates of interest, as younger people are even higher consumers of the internet than are members of older generations (Veenhof, 2006). As children are arguably the most vulnerable cohort, research on children and the internet is of high importance. The internet has become a feature of everyday living with limitless possibilities and unfiltered learning opportunities for children. Through the internet, children have access to worlds of knowledge and communication pathways. There is a controversial debate surrounding the topic of whether the benefits of the internet outweigh the harms of its use. Some believe that the internet can provide children with a cognitive advantage and excelled social skills. Others are cautious of the effect that early exposure to inappropriate content online can have on developing children (Albanese, 2020, p. 101). If left uncontrolled and unmediated, the internet has the potential to harm future generations of children because of the unfiltered nature of material posted online.

\section{Literature Review}

While considering the possibilities the internet can provide for children, it is essential to consider where children are permitted online access. Johnson (2010) conducted a study that focused on children's internet usage. Johnson had 38 Canadian children aged six to nine complete a 10-item rating scale. This method used a Likert-type scale that attempted to measure children's internet use at school and home. Johnson's scale used simple statements such as "I use the internet at home" that were easily understood by his participants given their age range (p. 286). After receiving the question, children were instructed to answer whether the statement was never, some- 
times, or often true. The results of the study demonstrated that approximately $90 \%$ of the participants reported using the internet at school, while $64 \%$ used the internet at home. These results suggest that children use the internet more at school than at home, but both statistics show high amounts of internet use. Johnson was able to classify the participants into three groups: homebased users, school-oriented information seekers, and school-oriented communicators. The homebased seekers enjoyed using the internet at home primarily for online gaming purposes. The school-oriented information seekers used the internet to search for information both at home and in school, with a preference for school research. The school-oriented communicators used platforms such as e-mail both at home and school, with a preference for school communication (Johnson, 2010). Through these results, it is clear that children are familiar enough with the internet to develop preferences for where and how they like to use it. However, no matter where and how they use it, the key takeaway from this study is that children are active users of the internet. Due to this finding, it is vital to discover why children are using the internet and the effects this use can have on them.

Valkenburg and Soeters (2001) conducted a study that focused on why children use the internet and the types of experiences they have while online. The researchers surveyed 194 participants aged eight to thirteen years old. The researchers asked the children how much time they spent on the internet, their motives for doing so, and any positive or negative occurrences experienced through the internet. Valkenburg and Soeters found that children claimed to use the internet primarily due to their love of computers. Affinity for computers was their top-rated motive, followed by researching information and entertainment purposes. The participant's most frequent positive experience on the internet was playing and downloading computer games. This was followed by watching videos, using children's entertainment websites, and learning about animals.

$24.7 \%$ of the participants reported experiencing adverse events on the internet (Valkenburg \& Soeters, 2001). Computer viruses were ranked as the most common adverse experience, followed by violence and pornography. The predominant negative experiences reported by the children were only somewhat associated with the hypothesized exposure to inappropriate material and harassment. The results from this study demonstrate that children utilize the internet for specific purposes. Additionally, the results showed that children experience both positive and negative events while online and are able to remember these events. With Valkenburg and Soeters' (2001) study in mind, it is necessary to consider how children's experiences online can affect them outside of the online world in aspects such as personal characteristics.

Jackson et al. (2011) conducted a study that focused on the internet's effects on children's academic performance and self-esteem. This study recruited 482 children from the seventh grade with a median age of approximately twelve years old. Participants' reading skills were assessed in small groups through the use of the Wide Range Achievement Test. Self-esteem was measured using Harter's Self-Competence Scale, which uses a Likert-type scale to assess children's perception of themselves. Jackson et al. (2011) found that children who used the internet more often scored higher on reading comprehension tests than those who were online less often. They also found that children who used the internet more had higher scores on the self-esteem scale. These results demonstrate that utilization of the internet could positively influence children's reading comprehension skills and self-esteem. Both of these qualities are highly valued in today's 
society and are therefore worthy of improvement efforts.

A study conducted by Molina et al. (2007) sought to see whether children's predetermined characteristics affected their online behaviours and consumption patterns. The researchers took children aged ten to twelve years old and collected data such as their gender, state of health, and familial education levels. Education level was a factor of particular interest to Molina et al. (2007) as they found it was associated with how people choose to spend their time. Another factor of high interest was gender, as it was associated with how children spend their time specifically online. Due to this connection, the study focused broadly on children's use of the internet for communication purposes and gaming purposes. The researchers used data from the Spanish Time Use Survey to created questions and applied them to child participants through a diary method. This method allowed for more accurate data than recall because it required participants to record their daily activities in ten-minute intervals. Molina et al. (2007) found that being female generated a positive influence on the time children spent on online communications. Molina et al. (2007) also found that being a boy positively influenced the time children spent on gaming. Other results from their study indicated that children with better health spent more time online. Additionally, parents with higher educational levels positively influenced their children's amount of time on the internet. Overall, these results demonstrate that gender could influence the time children devote to specific online activities. Molina et al.'s (2007) results suggest that as long as children have privacy protection and internet safety knowledge, spending time on the internet can be a sign of good health and education. However, while the internet can be helpful to some children, others may show signs of problematic internet use.

Wang and Cheng (2021) conducted a study that focused on children's internet behavior and the prevalence of problematic internet use. The researchers recruited 775 participants consisting of elementary school students in grades five and six. These nine- to twelve-year-old students were used as they were assumed to have obtained internet knowledge when they began taking computer classes in grade three. The researchers used the Problematic Internet Use Scale, which focuses on preferred online social interaction, time management, compulsive internet use, interpersonal influence, academic influence, daily life influence, and emotional adjustment influence. Wang and Cheng (2021) set out to understand the relationship between children's characteristics, their internet behaviours, and whether a particular combination of these variables could lead to problematic internet use. The results demonstrated that internet education at school impacted recreational internet experiences. Results showed that at home, parents had rules regarding internet use and consumption limits. The researchers found that there was only a low level of problematic internet use among participants and that the most prominent problem was poor time management. It was also found that when parents allowed their children to use the internet unrestricted and unsupervised, children showed more problematic internet use. Parents who established strict rules and time limits on internet usage raised children who were at low risk for problematic internet use, as they utilized the internet mainly for learning purposes. The children who used the internet strictly for learning purposes showed less problematic internet use than those who used it for entertainment and social media. Wang and Cheng (2021) concluded that there was a relationship between children's characteristics, their internet behaviours, and problematic internet use. The researchers suggest this relationship should lead parents to develop interventional strategies to prevent problematic internet use in their children. However, parents use different 
mediation strategies that call into question which method is the best option for monitoring children's internet use.

Livingstone et al. (2017) conducted a study that focused on the mediation styles that parents use to maximize their child's online opportunities while controlling for risks. This study surveyed the parents of 6,400 six- to fourteen-year-old children to assess their mediation strategies and the resulting outcomes. Livingstone et al. (2017) found that parents utilize two main strategies for mediating their children's internet use: enabling and restricting. The enabling strategy focuses on building a safe internet environment that encourages children to explore online opportunities. This strategy was connected to increased opportunities and increased risks online. The enabling strategy was used by parents who were found to be somewhat digitally skilled. This strategy was found to create increased child agency while employing safety efforts. The restrictive strategy was used by parents who believed the internet to be a risky environment deemed unsafe for children. This strategy was associated with fewer online risks and fewer opportunities. The restriction strategy was used by parents who demonstrated lower digital skills, and the strategy focused on the harms of problematic internet use. Hence, this strategy led to increased safety for children coupled with digital exclusion and reduced child agency. To find a compromise between strategies, Livingstone et al. (2017) suggest education for both parents and children that centres on how to use the internet safely. This strategy would involve highlighting the opportunities that the internet can provide while discussing the possible risks. By improving digital skills, those uncomfortable with the internet will become more knowledgeable and may drift away from the restrictive approach. This will expand the child's online opportunities. Parents who take a more laid-back approach to their child's internet use may be able to decrease their child's internet risks through learning more about the dangers of the internet environment. Combining parental mediation strategies could provide a compromise between opportunities and risks while combating problematic internet use.

\section{Conclusion}

This paper reviewed where children use the internet, why they use the internet, and the types of experiences they have online (Johnson, 2010; Valkenburg \& Soeters, 2001). The discussion continued with the internet's effect on a child's personal qualities and the relation between a child's predetermined traits and their consequential internet consumption (Jackson et al., 2011; Molina et al., 2007). Finally, topics such as problematic internet use and parental mediation styles were thoroughly reviewed (Livingstone et al., 2017; Wang \& Cheng, 2021). When taken together, these studies suggest the effects, outcomes, and possible solutions pertaining to children's internet usage. The literature has posed that the internet can influence children's lives in many ways, both positive and negative. Current research is inconclusive as to whether there are more positive or negative effects provided through internet use. However, this strengthens the hypothesis that children should have restricted access to the internet. Research by Livingstone et al. (2017) has shown that one of the most plausible ways to increase cognitive and social advantages while minimizing exposure to inappropriate content online is through parental intervention and mediation. If used efficiently, this strategy will allow children to continue to reap the benefits of the internet while minimizing its consequences. As suggested by Livingstone et al. 
(2017), this can be achieved through a particular parenting practice that combines enabling and restrictive internet mediation styles. Future research in this area could focus on the effects of this practice in order to assess whether it is truly a reliable method to combat online risks while promoting opportunity. Internet use is on an uphill trend in today's society and will continue to be a large part of children's lives. Education about the internet would be beneficial for both parents and children to promote familiarity and online safety. Using this knowledge, parents will ultimately decide on the appropriate amount of internet use for their children to undergo, while children can continue to acquire the valuable advantages of the online world. 


\section{References}

Albanese, P. (2020). Children in Canada Today (Third Edition). Toronto: Oxford University Press.

Jackson, L. A., Eye, A. V., Fitzgerald, H. E., Witt, E. A., \& Zhao, Y. (2011). Internet use, videogame playing and cell phone use as predictors of children's body mass index (BMI), body weight, academic performance, and social and overall self-esteem. Computers in Human Behavior, 27(1), 599-604. https://doi.org/10.1016/j.chb.2010.10.019

Johnson, G. M. (2010). Young Children's Internet Use at Home and School: Patterns and Profiles. Journal of Early Childhood Research, 8(3), 282-293. https://doi.org/10.1177/1476718X10379783

Livingstone, S., Ólafsson, K., Helsper, E. J., Lupiáñez-Villanueva, F., Veltri, G. A., \& Folkvord, F. (2017). Maximizing Opportunities and Minimizing Risks for Children Online: The Role of Digital Skills in Emerging Strategies of Parental Mediation. Journal of Communication, 67(1), 82-105. https://doi.org/10.1111/jcom.12277

Molina, J. A., Campaña, J. C., \& Ortega, R. (2017). Children's interaction with the Internet: time dedicated to communications and games. Applied Economics Letters, 24(6), 359-364. https://doi.org/10.1080/13504851.2016.1192270

Valkenburg, P. M., \& Soeters, K. E. (2001). Children's Positive and Negative Experiences With the Internet: An Exploratory Survey. Communication Research,28(5), 652-675. https://doi.org/10.1177/009365001028005004

Veenhof, B. (2006). The Internet : is it changing the way Canadians spend their time? Statistics Canada.

Wang, T. H., \& Cheng, H. Y. (2021). Problematic Internet use among elementary school students: prevalence and risk factors. Information, Communication \& Society, 24(2), 219-240. https://doi.org/10.1080/1369118X.2019.1645192 